\title{
Flexure and bonding behaviour of glass fiber reinforced epoxy resin composite beam under two point loading mechanism.
}

\author{
${ }^{1}$ Srinath T, ${ }^{2}$ Shyam Kumar E, \\ ${ }^{1,2}$ Assistant professor Department of Civil Engineering, Sri Shakthi Institute of Engineering and Technology, \\ Coimbatore.
}

\begin{abstract}
Glass Fiber - reinforced polymer (GFPR) has been used as an alternative to steel due to high strength -to-weight ratio, high stiffness- to - weight ratio and corrosion and fatigue resistance.GFRP have been found to be more attractive in asian region due to their cost competitiveness. Hence effort is required to find the bonding and flexural behaviors of fiber reinforced composite( $F R C)$ beam made using epoxy resin and glass fiber sheet with Triethylenetetramine (TETA) as hardener for curing of resin. To achieve the objective, an experimental setup was prepared with, specimen of hollow square section is casted and two point loading was applied to specimen. This will help in finding the elastic nature of the section.
\end{abstract}

Keywords: GFRP,Epoxy Resin, Glass Fiber,TETA

\section{Introduction}

Composite materials are materials with two or more constituents combined to form a material with different properties than those of the individual constituents. Fiber reinforced composites (FRC) is a composite material that consists of two constituents: a series of fibers surrounded by a solid matrix. FRC is highperformance fiber composite achieved by cross-linking fiber molecules with resins in the FRC material matrix through a proprietary molecular re-engineering process, yielding a product of exceptional structural properties. As with many other composite materials such as reinforced concrete, the two materials act together, each overcoming the deficits of the other. Whereas the plastic resins are strong in compressive loading and relatively weak in tensile strength, the fibers are very strong in tension but tend not to resist compression. By combining these two materials, FRC becomes a material that resists both compressive and tensile forces well.

Objective

The main objective is to study the numerical and experimental Behavior of hollow square FRC beam under flexure. It also enables us to study the strength capacity of the FRCbeam.

\section{A. FIBER}

\section{Components Of Frc}

Fiber is a natural or synthetic substance that is significantly longer than its width. The strongest engineering materials often incorporate carbon fibers, for example fiber and ultra-high-molecular-weight polyethylene. Synthetic fibers are often being produced very cheaply and in large amounts compared to natural fibers. There are two major types of Fiber such as natural and man-made fibers. Here, we go for man-made fiber. Each fiber has its own property. Table-1 shows the some of the man-made fibers with their properties. A Fabric is defined as a manufactured assembly of fibers to produce a flat sheet of one or more layers of fibers. These layers are held together either by mechanical interlocking of fibers themselves or with a secondary material to bind these fibers together. Based on the orientation of the fibers used, and by the various construction methods used to hold the fibers together fabrics are categorized into Unidirectional Fabric, Woven Fabrics, Hybrid Fabrics, Multiaxial Fabrics.

Table-1 Types and Properties of fiber

\begin{tabular}{|l|l|}
\hline Fibers & Properties \\
\hline Glass Fibers & Strength, Elasticity, heat resistance, \\
& Moisture resistance, Chemical \\
& resistance, Thermal conductivity, \\
& Electrical properties, High strength, \\
& Lightweight \\
\hline Wood Fibers & Flexural strength, Tensile modulus, \\
& Tensile Strength \\
\hline Carbon and Aramid Fibers & $\begin{array}{l}\text { High stiffness to weight ratio, High } \\
\text { strength, Corrosion resistant, Fatigue }\end{array}$ \\
& resistant, Energy Absorption on \\
& Impact, Tailored material properties \\
\hline
\end{tabular}




\section{B. RESIN}

The resins that are used in fiber reinforced composites can also be referred to as 'polymers'. All polymers exhibit an important common property that they are composed of long chain-like molecules consisting of many simple repeating units. Man-made polymers are generally called synthetic resins that act as bonding agent and also transfers stress between reinforcing fibers and to protect them from mechanical and environmental damage. Polymers can be classified into thermoplastic and thermosetting resin, according to the effect of heat on their properties. A thermosetting plastic, also known as a thermoset polymer material that irreversibly cures by heat, generally above $200^{\circ} \mathrm{C}\left(392^{\circ} \mathrm{F}\right)$, through a chemical reaction, or suitable irradiation. Thermoset materials are usually liquid or malleable prior to curing and designed to be moulded into their final form, or used as adhesives. Once hardened a thermoset resin cannot be reheated and melted to be shaped differently. A thermoplastic or thermo softening plastic is a polymer with high molecular weight that becomes pliable above a specific temperature, and returns to a solid state upon cooling. The polymer chains associate through intermolecular forces, which permits thermoplastics to be remoulded. Few resins and their properties are tabulated in Table-2

From the review of literature, it is found that the type and orientation of Fibers, type of resin affects the strength of FRC material. Strength of FRC section also depends on its Structural shape, where previous literatures are available for Box and I-sections. Here Hollow square beam sections are focused. Selection of correct combination of resin and fibers will be a challenge. Here we use Epoxy resin and Glass fibers as it is considered to be stronger than other combinations as well as Economic.

Table-2 Properties and Application of resins

\begin{tabular}{|l|l|l|}
\hline Resins & Application & Properties \\
\hline Polyester & Transportation and marine & $\begin{array}{l}\text { Excellent resistance to water and acidic } \\
\text { environments }\end{array}$ \\
\hline Vinyl ester & $\begin{array}{l}\text { Corrosion application such as } \\
\text { tanks, pipes and ducts }\end{array}$ & Resistance to Aggressive environments \\
\hline Phenolic resins & $\begin{array}{l}\text { Mass Transit - Fire Resistance } \\
\text { \& High Temperature }\end{array}$ & $\begin{array}{l}\text { Low flammability, low smoke } \\
\text { production }\end{array}$ \\
\hline Epoxy resins & $\begin{array}{l}\text { FRC Strengthening Systems, } \\
\text { FRC Rebar, FRC Stay-in- } \\
\text { Place Forms }\end{array}$ & $\begin{array}{l}\text { excellent electrical insulation, are less } \\
\text { affected by water and heat, low } \\
\text { shrinkage, high strength, low toxicity }\end{array}$ \\
\hline
\end{tabular}

\section{EPOXY RESIN}

\section{Material Collection And Testing}

Epoxy resins are low molecular weight pre-polymers or higher molecular weight polymers which normally contain at least two epoxide groups. The epoxide group is also sometimes referred to as a glycidyl or oxirane group. Epoxy resins may react (cross-linked) either with themselves through catalytic homo polymerization, or with a wide range of co-reactants including poly functional amines, acids (and acid anhydrides), phenols, alcohols and thiols. These co-reactants are often referred to as hardeners or curatives, and the cross-linking reaction is commonly referred to as curing. Reaction of polyepoxides with themselves or with poly functional hardeners forms a thermosetting polymer, often with high mechanical properties, temperature and chemical resistance. Testing and results of epoxy resin are given below in table -3 .

Table-3 Chemical Properties of Resin

\begin{tabular}{|l|l|l|l|l|}
\hline S.no. & Tests performed & Test method & Specification & Results \\
\hline 1. & Visual appearance & In house & Clear liquid resin & Clear liquid resin \\
\hline 2. & Color Index, Gardner & ISO-4630-2 & $0-1$ & 0.1 \\
\hline 3. & Epoxide index (Eq/Kg) & ISO-3001 & $5.3-5.45$ & 5.43 \\
\hline 4. & $\begin{array}{l}\text { Viscosity dynamic at 250C , } \\
\text { mPa.s }\end{array}$ & ISO- 12058 & $10000-12000$ & 10250 \\
\hline 5. & $\begin{array}{l}\text { Chlorine content (hydrolysable), } \\
\text { ppm }\end{array}$ & AMTM 116 & $0.0-400$ & 240 \\
\hline
\end{tabular}

\section{HARDENER}

Hardeners are substances that are used for the setting/Curing of the resins. The chemical hardener used here is "Triethylenetetramine". It is primarily used as a cross linker in Epoxy curing. Triethylenetetramine abbreviated TETA and trien, is an organic compound with the formula [CH2NHCH2CH2NH2]2.It is soluble in polar solvents and exhibits the reactivity typical for amines. For FRC using epoxy resin, the mix proportion is 150 grams of hardener is mixed with 1000 grams of Epoxy resin as per company recommendation. Tests and results of TETA are given in table- 4 . 
Table-4 Chemical Properties of Hardener

\begin{tabular}{|l|l|l|l|l|}
\hline S.no & Tests parameter & Test method & Specification & Results \\
\hline 1. & Appearance & Visual & $\begin{array}{l}\text { Colorless to pale yellow } \\
\text { liquid without impurities }\end{array}$ & OK \\
\hline 2. & $\begin{array}{l}\text { Color index } \\
\text { ALPHA }\end{array}$ & ISO- 6271-1 & $0-50$ & \\
\hline 3. & $\begin{array}{l}\text { Viscosity dynamic at } \\
250 \mathrm{C}, \text { mPa.s }\end{array}$ & ISO- 12058-1 & $10-20$ & 14 \\
\hline 4. & Moisture content. \% & ISO- 760 & $0-0.5$ & 0.3 \\
\hline
\end{tabular}

\section{E. GLASS FIBER}

Glass Fibers are among the most versatile industrial materials known today. Fiberglass is much more sustainable than Aluminium, steel or timber. There are no large smoke plumes or other forms of environmental pollution from the manufacture of fiberglass. They exhibit useful properties such as hardness, transparency, resistance to chemical attack, stability, and inertness, as well as desirable fiber properties such as strength, flexibility, and stiffness. This acts as the reinforcing material in FRC. Glass reinforcements used for fiberglass are supplied in different physical forms such as microspheres, chopped or woven and reinforcing bars which are given in Fig-1. Glass fibers are categorized into Low-cost General-Purpose fibers and Premium special-Purpose fibers. Over $90 \%$ of all glass fibers are general-purpose products.

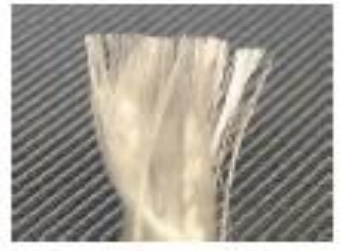

(a) Microspheres

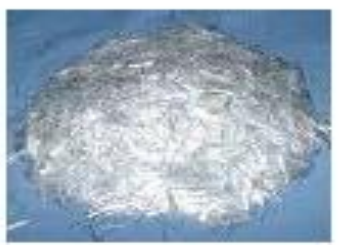

(c) Chopped strand

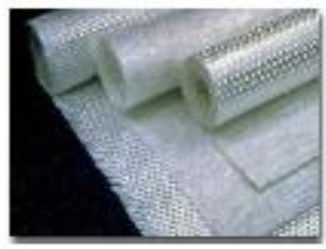

(b) Woven Roving

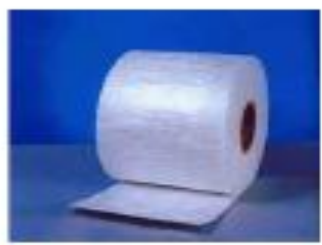

(d) Chopped strand mat

Fig-1 Forms of Fiber Reinforcement

\section{A. FRC HAND LAY-UP PROCESS}

\section{Specimen Casting And Analysis}

A release agent, either in wax or liquid form, is applied to the chosen mould. This will allow the finished product to be removed cleanly from the mould. Resin is mixed with its hardener and applied to the surface. Sheets of fiber matting are laid into the mould, then more resin mixture is added using a brush or roller. The material must conform to the mould, and air should not be trapped between the fiber and the mould. Additional resin is applied and possibly additional sheets of fiber. Hand pressure, vacuum or rollers are used to make sure the resin saturates and fully wets all layers, and any air pockets are removed. The work must be done quickly enough to complete the job before the resin starts to cure, unless high temperature resins are used which will not cure until the part is warmed in an oven. In some cases, the work is covered with plastic sheets and vacuum is drawn on the work to remove air bubbles and press the FRC to the shape of the mould. The process is explained in Fig-2.

\section{B. CASTING PROCEDURE}

Mould is prepared according to the dimensions mentioned in table-5. The casting is done by Hand Layup Process which is the most common and easy method. A chemical resistant film coating is given along the surface of the mould to ease up the releasing process once the specimen is cured. The resin and hardener is mixed together according to the mix proportion as per the manufacturer's recommendations. Then a thin coat of the resin mixture is applied over the mould which is shown in Fig-3. Once the layer starts to harden, then the glass fiber sheet is placed over it and again the resin is applied on it by a paint brush or a roller as shown below in Fig-4. This process will continue in a cyclic manner until the desired thickness has been achieved. 16 coats of 
fiber and resin is coated to get an effective thickness of $15 \mathrm{~mm}$. Only $4 \mathrm{~mm}$ were fabricated per day as the chemical reactions are exothermic and would release enormous amount of heat during the curing process. It took a total of 4 days to complete the casting and curing of the specimen.

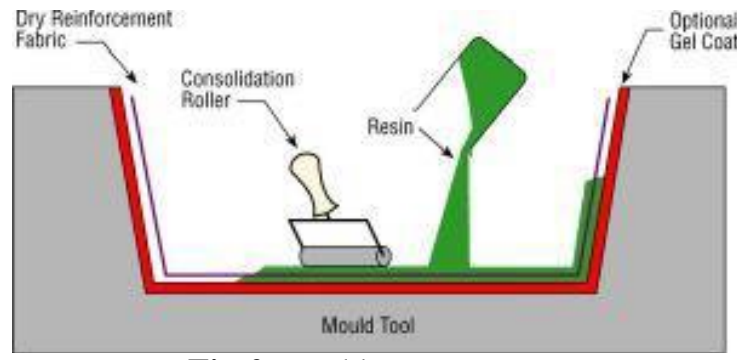

Fig-2 Hand lay-up process

Table-5 dimensions and properties of specimen

\begin{tabular}{|l|l|}
\hline Prop erty & Dimension \\
\hline Shape & Hollow square section. \\
\hline Side & $100 \mathrm{~mm}$ x 100mm \\
\hline Length & $1000 \mathrm{~mm}$ \\
\hline Thickness & $15 \mathrm{~mm}$ \\
\hline Support condition & $\begin{array}{l}1 \text { end is hinged, other end is roller } \\
\text { supported }\end{array}$ \\
\hline Young's modulus & $39 \mathrm{GP}$ \\
\hline
\end{tabular}

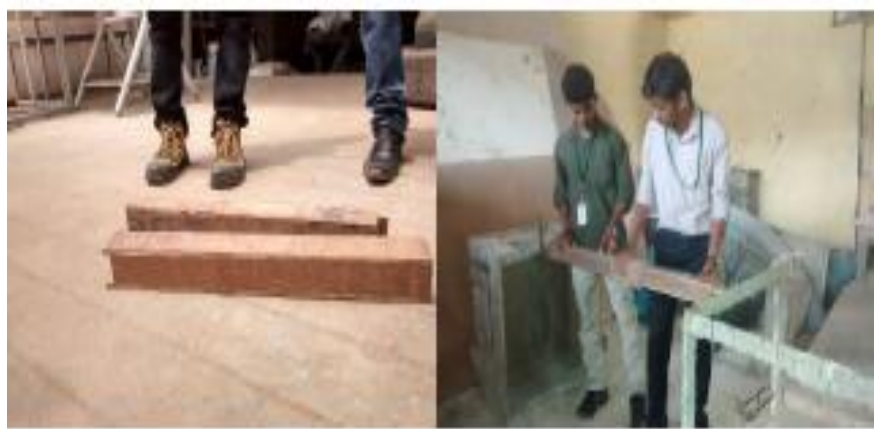

Fig-3 Casting of specimen

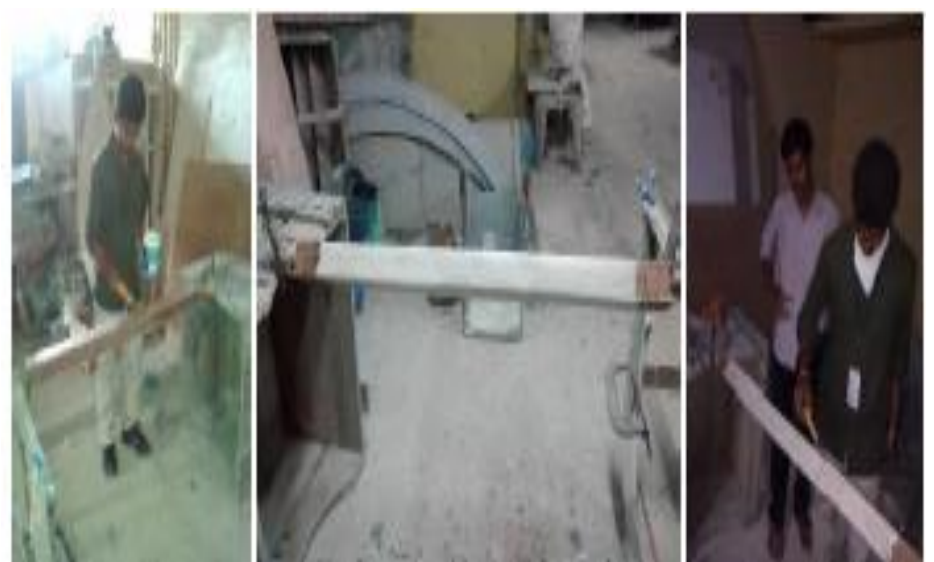

Fig-4 Casting of Specimen-FRC layers

\section{THEORETICAL ANALYSIS}

The beam is theoretically analyzed by the following formula.

$\Delta=(\mathrm{Pa} / 24 \mathrm{EI})(312-4 \mathrm{a} 2)$

Where the deflection result are tabulated in Table- 6 
Table-6 theoretical result

\begin{tabular}{|l|l|}
\hline Load & Deflection $(\mathbf{m m})$ \\
\hline 10 & 1.159 \\
\hline 15 & 1.739 \\
\hline 20 & 2.319 \\
\hline 25 & 2.89 \\
\hline 30 & 3.47 \\
\hline 35 & 4.05 \\
\hline 40 & 4.639 \\
\hline 45 & 5.21 \\
\hline 50 & 5.79 \\
\hline 55 & 6.379 \\
\hline 60 & 6.95 \\
\hline 65 & 7.539 \\
\hline 70 & 8.119 \\
\hline 145 & 16.81 \\
\hline
\end{tabular}

\section{EXPERIMENTAL ANALYSIS}

The section was analyzed using loading frame Capacity of 50 tonne. The experimental setup is shown below in Fig-5. A two point loading was applied to the specimen at a distance of $250 \mathrm{~mm}$ from both ends. The values for loads and deflection are tabulated in table-7 below.

Table-7_Experimental result

\begin{tabular}{|l|l|}
\hline Load & Deflection $(\mathbf{m m})$ \\
\hline 10 & 0.7 \\
\hline 15 & 1.1 \\
\hline 20 & 1.95 \\
\hline 25 & 2.55 \\
\hline 30 & 3.40 \\
\hline 35 & 4.10 \\
\hline 40 & 5.70 \\
\hline 45 & 6.40 \\
\hline 50 & 7.20 \\
\hline 55 & 8.30 \\
\hline 60 & 8.90 \\
\hline 65 & 8.2 \\
\hline 70 & 9.70 \\
\hline 145 & 12.3 \\
\hline
\end{tabular}

\section{Results And Discussion}

The summary of theoretical and experimental study results of our specimen is discussed in this paper. In the experimental study, the column will be able to withstand loads around $1500 \mathrm{kN}$, but due to practical difficulty the experiment was stopped at $540 \mathrm{kN}$, as the loading frame was limited to 50 tonnes. The load deflection curve is shown below in fig- 6 and fig- 7 .

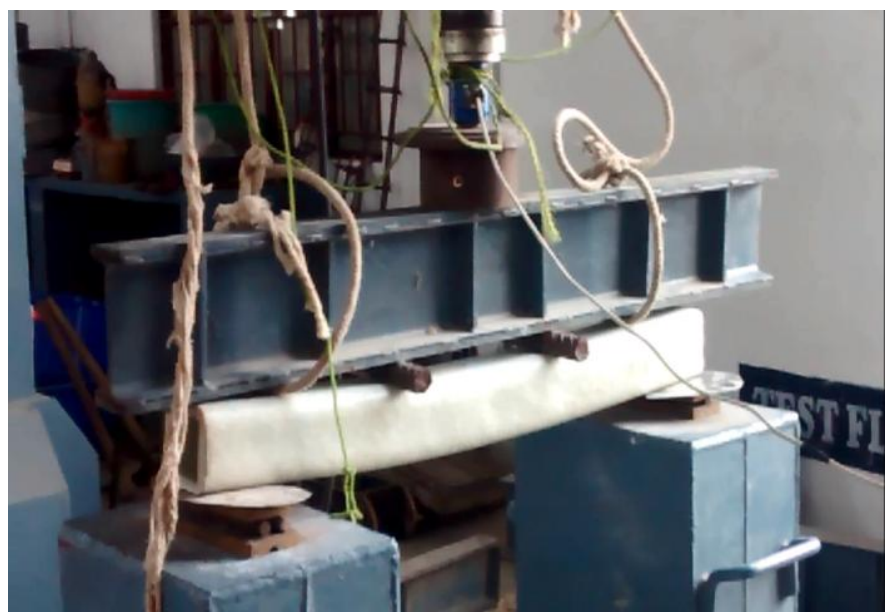

Fig-5 loading setup-deflection mode 


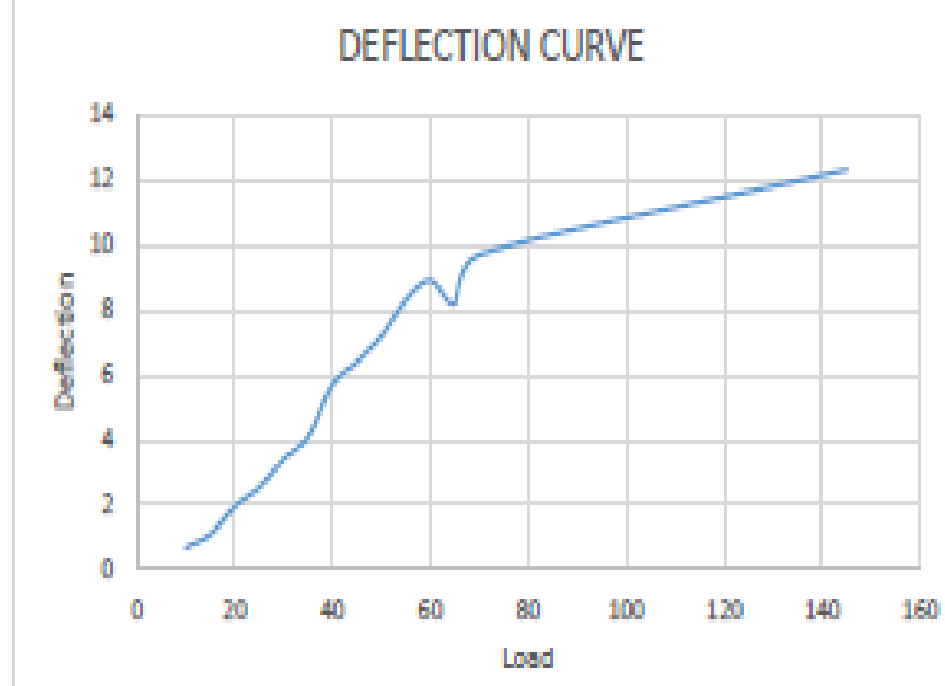

Fig-6 Load vs deflection curve for experimental analysis

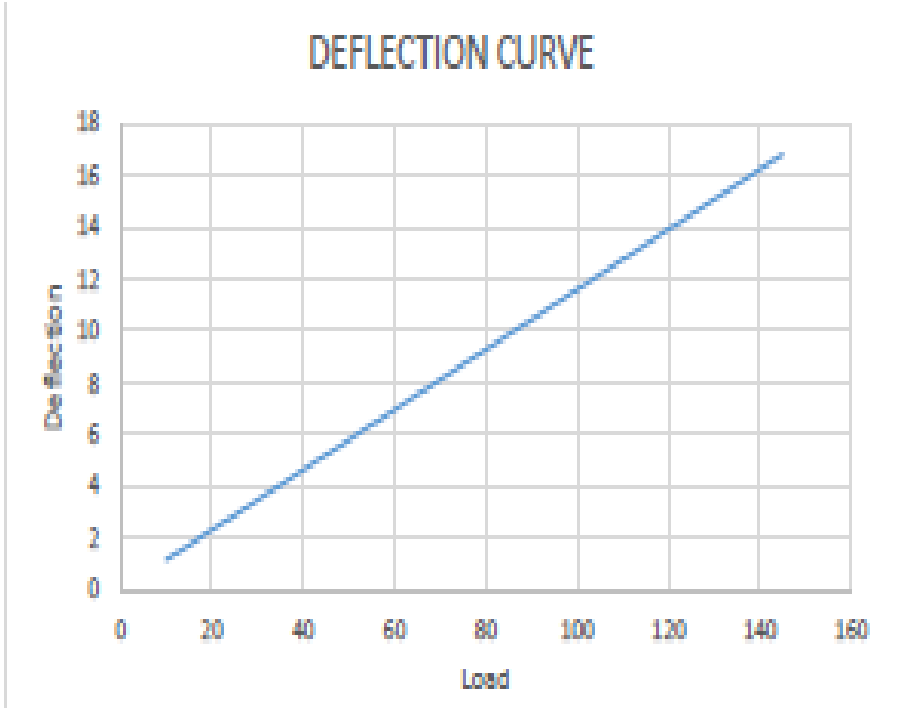

Fig-7 Load vs deflection curve for theoretical analysis

\section{Conclusion}

Our FRC Beam is tested experimentally and theoretically, which gives more over similar results. So we convince with our result that our FRC Beam can carry more weight with good elastic nature and restore to its original position when the load is removed. The FRC is also weightless in nature which makes it easier for transportation and hoisting. It is also resistant against corrosion. With these many advantages, FRC can be used at places where conventional steel or concrete cannot be used.

\section{A. WARPING}

\section{Fre- Limitations}

One notable feature of FRC is that the resins used are subject to contraction during the curing process. For polyester this contraction is often of the order of 5-6\%, and for epoxy it can be much lower, about $2 \%$.

When formed as part of FRC, because the fibers don't contract, the differential can create changes in the shape of the part during cure. Distortions will usually appear hours, days or weeks after the resin has set.

\section{B. HEALTH PROBLEMS}

Inhaling these fibers can reduce lung function and cause inflammation in animals and humans. FRC can cause skin, eye and throat irritation. At higher exposure levels, FRC also has been associated with skin rashes and difficulty in breathing. 


\section{References}

[1] Barbero E J, Raftoyiannis I G, "Euler buckling of pultruded composite columns". Composite Structures, 1993, $24(2)$ : $139-147$.

[2] Correia, M.M, Correia,J. ,Nunes.F., Silvestre,N. , ,"Experimental and numerical study on the structural behavior of eccentrically loaded GFRC columns." Thin-Walled Structures, 2013, 72, 175-187.

[3] Ever Barbero and John Tomblin ,"Local Buckling Experiments on FRC Columns", Thin-Walled Structures , 1994 (18): $97-116$.

[4] Ever J. Barbero and Malek Turk, "Experimental Investigation of Beam-Column Behavior of Pultruded Structural Shapes", Journal of Reinforced Plastics and Composites, 2000, vol. 19.

[5] J.F.Davalos*, H. A. Salim, P. Qiao, R. Lopez-Anido, "analysis and design of pultruded FRC beams in bending".

[6] Pizhong Qiao, Julio F. Davalos, and Jialai Wang, "Local Buckling of Composite FRC shapes by Discrete Plate Analysis", Journal of Structural Engineering, March, 2001, Vol. 127, No. 3,

[7] Sang Kyoon Jeong and Soon Jong Yoon, "Elastic Buckling of Orthotropic Open Section Compression Members with Edge Stiffeners". KSCE Journal of Civil Engineering, 1998, Vol.2, 377-386. 